\title{
Exploring the design and development of an "On-the-shell" tumbling mill acoustic monitoring system
}

Suda Martins, Joachim Zepeda, Benoit Picard, Peter Radziszewski

Department of Mechanical Engineering

McGill University

In the mineral processing industry, tumbling mills are used in the size reduction or comminution of ore to a target size distribution. As the tumbling mill environment is quite violent it is difficult to monitor mill charge motion. One way is to develop an "onthe-shell" acoustic system. This system will be used in the determination of the charge toe angle of an operating tumbling mill. The instrument, microphone system with the appropriate data acquisition system, collects the acoustic data. An analysis of the signal determines the location of the toe. The results of this development along with some trial data are presented. 